\title{
3D DISPLAY INTERFACES IN E-COMERCE WEB APPLICATIONS: AN EXPLORATORY STUDY
}

\section{Interfaces 3D en aplicaciones web de comercio electrónico: un estudio exploratorio}

\author{
Alexey Chistyakov, María T. Soto-Sanfiel, Takeo Igarashi, Daisuke Sakamoto \\ and Jordi Carrabina
}

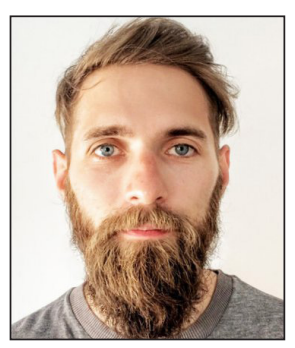

Alexey Chistyakov is a computer science doctoral student at the Computer Science Department at Universitat Autònoma de Barcelona (UAB). He holds a B.A. in Biomedical Engineering obtained in 2005, and a M.Sc. in Multimedia Ambient Intelligence in 2013. Currently he is working on a PhD in Computer Science. His main research interests are in investigation of human-computer interaction, specializing in user experience and user interaction with virtual reality, augmented reality and 3D display interfaces.

https://orcid.org/0000-0001-8659-6463

Universitat Autònoma de Barcelona, Spain Department of Computer Science alexey.chistyakov@e-campus.uab.cat

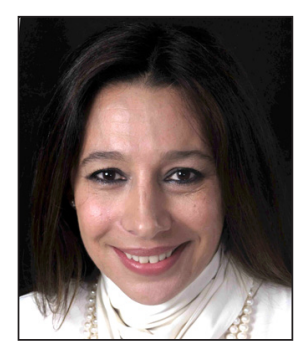

María T. Soto-Sanfiel (aka Maite) is an associate professor at the Audiovisual Communication and Advertising Department at Universitat Autònoma de Barcelona (UAB). She received a B.A. in Social Communication, Advertising and Public Relations (UCAB). She obtained two master's degrees (New Audiovisual Technologies and Advertising, and Interactive Communications, Telecommunications and Multimedia) and her PhD in Audiovisual Communication, at UAB. Her main research interests are science communication, psychological reception of media message, cross-cultural reception, interactive storytelling, entertainment theories, and voice or sound perception in mediated context.

https://orcid.org/0000-0002-1364-8821

Universitat Autònoma de Barcelona, Spain Audiovisual Communication and Advertising Department mariateresa.soto@uab.es

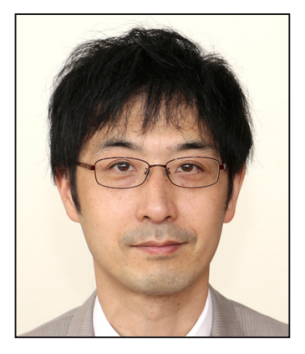

Takeo Igarashi received a PhD from the Department of Information Engineering at The University of Tokyo in 2000. He joined the Department of Computer Science as an assistant professor in 2002 and promoted to a professor in 2011. His research interest is in user interfaces and interactive computer graphics in general. He lead JST ERATO Igarashi Design Interface Project in 2007-2013, developing various content creation tools for graphics, fabrication, and robotic systems. He received The Significant New Researcher Award at Siggraph 2006.

https://orcid.org/0000-0002-5495-6441

The University of Tokyo, Department of Computer Science, Japan takeo@acm.org

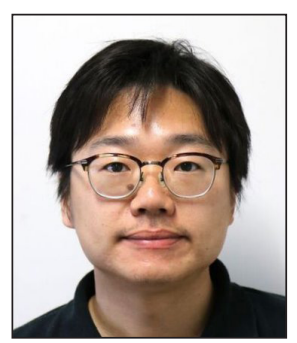

Daisuke Sakamoto is an associate professor of Human-Computer Interaction Lab, Hokkaido University. He received his B.A. Media Architecture, M. Systems Information Science, and Ph.D. in Systems Information Science from Future University-Hakodate in 2004, 2006, and 2008, respectively. He worked at The University of Tokyo as an assistant professor and a project lecturer. His research interests include Human-Computer Interaction and Human-Robot Interaction, which focused on the user interaction with people and interaction design for the computing systems.

https://orcid.org/0000-0002-2219-4198 


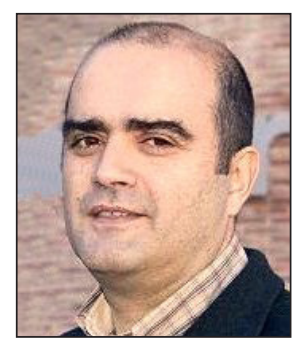

Abstract

The objective of the present research is to observe to what extent the stereoscopic effect presents a solution for enhancement of user interactions in the Web context. This paper describes an experiment conducted to detect differences in perception between 2D and 3D graphical user interfaces of an e-Commerce web application. The results of the conducted user study among 39 participants indicate significantly higher performance of the 2D interface in terms of efficiency, satisfaction, and, consequently, overall usability. Therefore, for the studied sample, the stereoscopic effect had mostly negative impact on user interactions.

\section{Keywords}

3D displays; Usability; Human-computer interaction; Stereoscopic effect; E-commerce; Web; Web applications.

\section{Resumen}

El objetivo de la presente investigación es observar hasta qué punto el efecto estereoscópico es una solución para mejorar la interacción del usuario en el contexto Web. Se describe un experimento llevado a cabo para detectar diferencias de percepción entre las interfaces gráficas de usuario 2D y 3D de una aplicación web de comercio electrónico. Los resultados del estudio de usuarios, llevado a cabo con 39 participantes, indican un rendimiento significativamente más alto de la interfaz 2D en términos de eficiencia, satisfacción y, en consecuencia, facilidad de uso general. Por lo tanto, para la muestra estudiada, el efecto estereoscópico tuvo un impacto mayormente negativo en las interacciones del usuario.

\section{Palabras clave}

Pantallas 3D; Usabilidad; Interacción persona-ordenador; Efecto estereoscópico; Comercio electrónico; Web; Aplicaciones web.

Chistyakov, Alexey; Soto-Sanfiel, María T.; Igarashi, Takeo; Sakamoto, Daisuke; Carrabina, Jordi (2018). "3D display interfaces in e-commerce web applications: An exploratory study". El profesional de la información, v. 27, n. 5, pp. 11161127.

https://doi.org/10.3145/epi.2018.sep.15

\section{Introduction}

Binocular vision was discovered by Wheatstone (Wheatstone, 1838) over a century ago. Since this discovery, stereoscopic 3D display technology has leapt from the first stereoscope to a booming market of 3D enabled devices: 3DTVs, monitors, projectors, handheld devices, headsets and more. The technology was somewhat abandoned in the middle of the $20^{\text {th }}$ century, but recently, has regained the interest of the scientific community due to the explosion of virtual reality (VR) applications. At the same time, just a few decades old World Wide Web (Web) technology spread widely to the extent where it is impossible to imagine a modern application without any relation to it; in the modern world, the Web has become nearly ubiquitous. Due to its open nature and ease to work with, the Web is the most popular platform among application developers currently available.

The interest from industry and academia to both technologies is on the rise. However, the combination of two technologies seems not having been explored sufficiently and still there is a goal of finding a proper way to apply the stereoscopic effect to web applications (webapps).
3D displays are already being successfully used in the fields of medicine (Van-Beurden; IJsselsteijn; Juola, 2012; Martínez-Escobar et al., 2015), robotics (Murray; Jennings, 1997; Murray; Little, 2000), industrial design (Fiorentino et al., 2002), education (Ilgner et al., 2006; Johnson et al., 2006; Heath; Cohen-Gadol, 2012) and many other applications. Moreover, in a recent comparative study (McIntire; Havig; Geiselman, 2014) participants viewing 3D displays demonstrated (E1) improved recall of scenes and objects, (E2) significant improvement in performance in a number of tasks involving finding, classifying and identifying objects, (E3) enhanced visual experience, immersion, and arousal, in comparison with 2D displays. These enhancements in task performance might have an impact on user interaction when it comes to the user interface design.

Modern webapps are often cluttered with functionality, multimedia content, controls, etc., which makes their graphical user interface (GUI) rather challenging to get a grip on. E1 and E2 could have a positive effect on this problem, while E3 could improve the user experience (UX) when it comes to the webapps GUI design. 
The e-commerce domain was chosen for this study as it is one of the main drivers of the success of Web technology. E-commerce webapps are in great demand and numerous; online shopping behavior is well established through years of e-commerce existence. Thus, it was chosen as a test paradigm for the present research.

The present study briefly outlines the efforts of the scientific community towards the research of user interaction with stereoscopic displays and committed attempts to introduce the stereoscopic effect into the Web environment. Further, the paper aims to understand the impact of the stereoscopic effect on the perception of the user interface of an e-commerce Web application by conducting an experiment in human subjects.

The literature shows an overwhelmingly positive impact of the stereoscopic effect on user performance in different tasks

\section{State of the art}

\subsection{D displays and applications}

In their review of the state of stereoscopic 3D technology, Holliman et al. (2011) suggest that the benefits of the stereoscopic effect are potentially attractive for a wide range of desktop and handheld tasks. The review concludes

"Stereoscopic and autostereoscopic technologies are now developed to a point where they are being used in everyday applications".

Moreover, McIntire, Havig and Geiselman (2012) (in a thorough analysis of the experiments made during the past few decades, show that, in the overwhelming majority of studies, S3D performs better than 2D.

Schild, LaViola and Masuch (2012) studied how the stereoscopic effect could influence the user experience when it comes to digital games. This comprehensive study concludes that the effect positively influences overall user experience and is clearly preferred over the monoscopic counterpart, increases experiences of presence and immersion while at the same time causing more symptoms of simulator sickness. A follow-up study (Schild et al., 2013) applied the stereoscopic effect to gaming GUIs and detected strong quality improvements in the gaming experience.

Overall, the literature shows an overwhelmingly positive impact of the stereoscopic effect on user performance in different tasks. However, a comprehensive review of works dedicated to the research of human interaction with stereoscopic displays by McIntire, Havig and Geiselman (2014) shows that in $25 \%$ of the 184 experiments covered by the review, S3D was of little or no help. The stereoscopic effect seemed to fail for well-learned tasks or for tasks that did not heavily rely on depth information. Additionally, McIntire et al. suggest that a disproportionate number of works that find no positive effects of S3D fail to be published and get abandoned.

\subsection{D displays in e-commerce applications}

First attempts to use 3D interface in e-commerce context go back to the year 2000. In their search for experiences "more natural, attractive, and fun for customers", Chittaro and Ranon (2000) experimented with so-called "walking products" - a 3D animated representation of products, and introduced Advirt (Adaptive VR store). Further, in pursuit for a general approach to build adaptive 3D web sites, the same researchers (Chittaro; Ranon, 2002), proposed Awe3D (Adaptive web 3D), a tool based on a combination of web technologies. Researchers outlined the main benefits of using a 3D display for e-commerce purposes. In their opinion, a 3D interface can bring relevant benefits:

i) it is closer to the real-world shopping experience, and thus more familiar to the customer;

ii) it supports customer's natural shopping actions;

iii) it can satisfy the needs of customers who have an emotional style of buying, by providing a more immersive, interactive, and visually attractive experience.

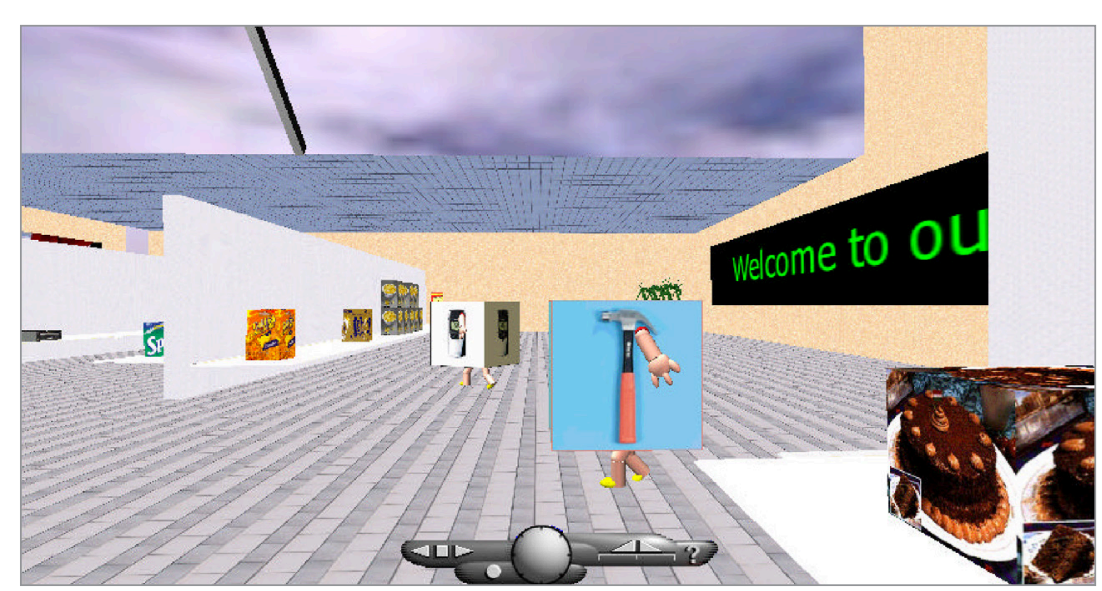

Figure 1. A first adaptation of Advirt by Chittaro et al.

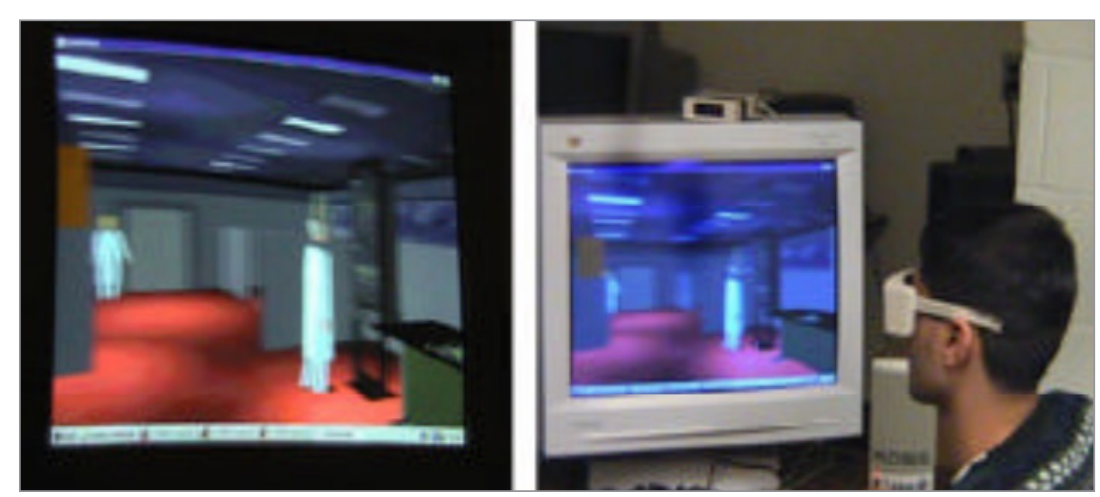

Figure 2. Stereoscopic version of the user interface prototype designed by De-Oliveira, Shen and Georganas (2000) 
At the same time De-Oliveira, Shen and Georganas (2000) proposed a prototype of a user interface for e-commerce in a virtual environment on the Internet, where users can use the UI to navigate the virtual world.

A recent literature review by Zeng and Richardson (2017) shows a steady growth in research on product presentation and virtual reality experience in e-commerce: 31 papers published over last 10 years account for $69 \%$ of the total studies and marks product presentation in VR as a "vital topic".

While researching impulsive online buying, Vonkeman, Verhagen and Van-Dolen (2017) found the reported that:

i) perceptions of local presence increase when products are presented in a vivid and interactive manner in a web store;

ii) perceptions of local presence increase the urge to buy impulsively through increased product affect;

iii) although local presence reduces perceived product risk, product risk does not inhibit the urge to buy impulsively.

It is important to note, that the terms 3D and VR in the covered context does not imply usage of $3 D$ display technology. The scope of this work is narrowed down to the study of perception and interactions with stereoscopic 3D environments and application of 3D display technology on the e-commerce context. A stereoscopic effect can create a high sense of presence and vividness (Yim; Cicchirillo; Drumwright, 2012). 3D display interfaces can noticeably enhance product presentation in 3D e-commerce applications.

\subsection{D display user interface development}

The work of González-Zúñiga et al. (2013) detected disturbances in well-established web perception patterns (Figure 3) caused by introduction of stereoscopic effect into GUI layout. An eye-tracking study confirmed the strong impact of presence of the stereoscopic depth in GUI layout, thereby outlining the necessity of further research of interaction with S3D UIs. Moreover, in his review (Ortiz Jr., 2010) of current web technology, Ortiz predicts

"3D on the web will do as well as video on the web has done".

Currently, the implementation of the stereoscopic depth in the layout of user interfaces remains challenging. However,

a number of attempts (Johnston; Renambot; Sauter, 2013; Chen et al., 2014; Perakakis; Ghinea, 2015; Chistyakov et al., 2016) have been made to create a framework for implementation of the stereoscopic depth into layout of the HTML pages. Those approaches successfully tackle this problem and provide researchers and practitioners with the possibility to design and develop stereoscopic UIs as easily as with any conventional HTML front-end.

Overall, the previous efforts suggest noticeable improvements and positive user acceptance. Moreover, in most of the reviewed cases 3D generally was preferred over 2D. This may be explained by a proven emotional impact (Seuntiëns et al., 2005) observed in stereoscopic applications.

\section{Method}

To better understand the impact of the stereoscopic effect on the usability of web applications, an experimental between-subjects exploratory study was designed and conducted. In correspondence with the hypotheses, the independent variable was defined as the display setup: 3D display (G3D) and 2D display (G2D) groups, while the dependent variables were defined as overall usability, efficiency, learnability, and satisfaction. A convenience sample was used.

\subsection{Participants}

A total of 39 participants including 32 male and 7 female subjects ( $N=39, M=28.538, S D=5.433, R g=21-42)$, who were students and staff of the Computer Science Department at the Universitat Autònoma de Barcelona $(N=6, M=25.670$, $S D=2.388, R g=23-30)$, the University of Tokyo $(N=16$, $M=25.5, S D=4.747, R g=21-37)$, and the CMP Group ( $N=17$, $M=32.410, S D=4.360, R g=23-42$ ) took part in the study. The sample included subjects of different nationalities from Asia, Europe, North and Central America, with a majority of participants (23\%) from Japan ( $N=9, M=24.560, S D=4.003$, $R g=22-32$ ). Data collection was performed during research visits of the authors to the aforementioned centers. Further, the participants were randomly assigned to one of 2 condition groups: 22 individuals were exposed to the stereoscopic version of a stimulus. Once the experimental group was completed, 17 other individuals observed the 2D version of the stimulus. Participation was anonymous and voluntary as no economical compensation was offered. The research was approved by the ethics committees at the respective institutions.

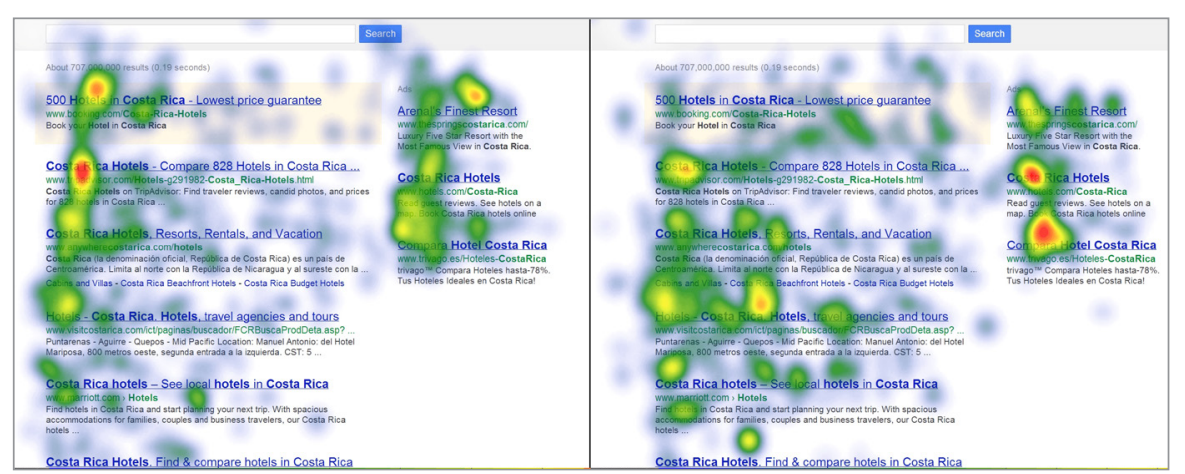

Figure 3. Gaze distribution heatmap laid over 2D (to the left) and 3D (to the right) web search engine results page as seen in (González-Zúñiga et al., 2013). Please note, in the 3D stimulus the block with advertising (to the right) is placed closer to the user in the stereo space resulting in higher concentration of the observers' attention

\subsection{Materials}

The stimuli were reproduced in Google Chrome browser using $\mathrm{Ma}$ cBook Pro PC (CPU: $2.8 \mathrm{GHz}$ Intel Core i7; RAM: DDR3 16GB) connected to a Sony PlayStation 3D display (Width: 650mm; Height: $387 \mathrm{~mm}$; Depth: screen $33 \mathrm{~mm}$, stand $280 \mathrm{~mm})$. The 3D stimulus was displayed in FullHD resolution (1920x1080px) to reach the resolution of the final stereoscopic composition of 720p (1280x720px). The 2D stimulus was downgraded 

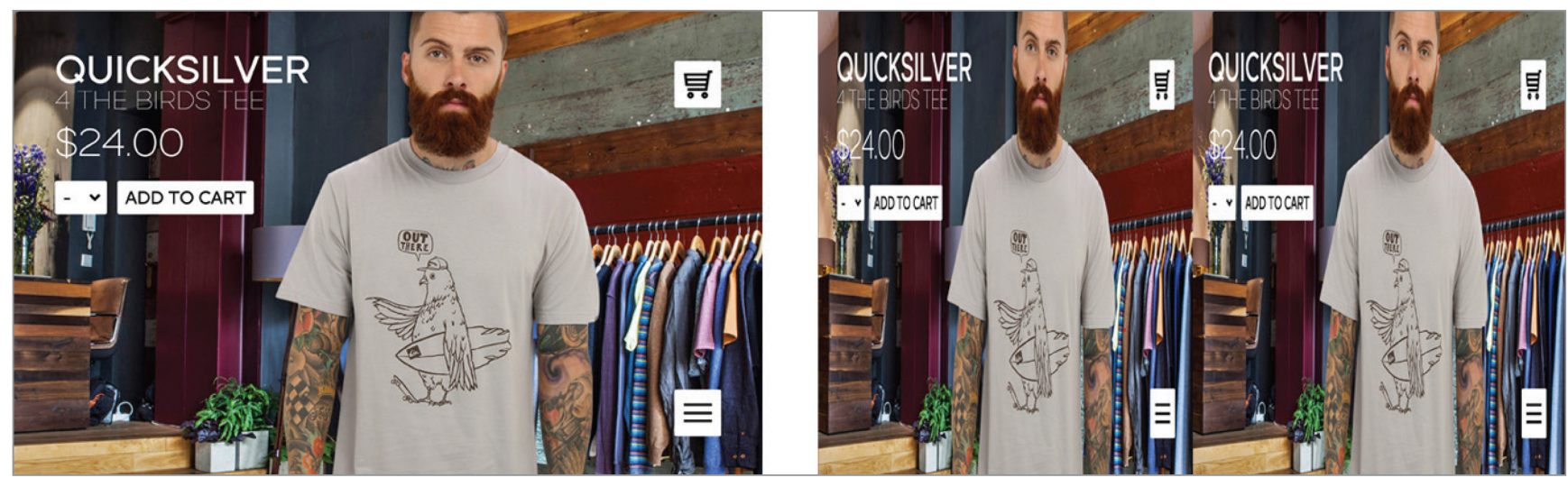

Figure 4. The 2D (to the left) stimulus and its stereoscopic (to the right) modification.

to the same resolution of 720p, to exclude the impact ( $\mathrm{Ha}$ yashi et al., 2000) of higher resolution on the subjective performance of the $2 \mathrm{D}$ stimulus. The participants of both groups were seated $(k=100 \mathrm{~cm}, S D=10 \mathrm{~cm})$ away from the display. For interaction with the 3D stimulus the participants in the corresponding group were equipped with PlayStation $3 D$ glasses. The only way of interacting with the stimuli was through the Apple Magic Mouse controller.

A user interface of a T-shirt web-shop application was designed as a stimulus to test the hypotheses. The application layout (see Figure 4) included:

i) background image;

ii) one photo of a model wearing a t-shirt in the center;

iii) a block with the name of the current t-shirt model, its price, the t-shirt size select control, and an "Add to cart" button on the top left;

iv) a shopping cart link on the top right, and (dv) the t-shirt model selector trigger on the top bottom.

The final application allowed a user to choose a model of a t-shirt, select a size of the t-shirt, and add the selected $\mathrm{t}$-shirt/size combination to a cart.

The stimulus was built using HTML and further converted into a side-by-side stereo-pair using 3DSjQ (Chistyakov et al., 2016). It was decided to define three depth levels to distribute the elements along the depth axis (see Table 1) and assign them to each level in the following order: screen plane $\mathrm{dlO}(\mathrm{h}=0 \mathrm{~cm},=0 \mathrm{deg})$ containing the background image, $d l 1(h=0.143 \mathrm{~cm}, \varphi=0.286 \pm 0.030 \mathrm{deg})$ containing the photo of a t-shirt model, and $d 12(h=0.214 \mathrm{~cm}, \varphi=0.428 \pm$ $0.048 \mathrm{deg}$ ) containing all the controls of the application. This way the group of elements responsible for interaction with the app (d/2) was put closer to the user, while the passive elements carrying mostly visual function were put farther
Table 1. Depth levels used for distribution of layout elements of the application. The numbers were calculated considering the display's pixel density of $(d=24.091 \mathrm{ppcm})$, and the distance between a participant and the display $(k=100 \mathrm{~cm}, S D=10 \mathrm{~cm})$.

\begin{tabular}{|l|c|c|c|}
\cline { 2 - 4 } \multicolumn{1}{c|}{} & dl0 & dl1 & dl2 \\
\hline Disparity $(h), \mathrm{cm}$ & 0 & 0.143 & 0.214 \\
\hline Horizontal visual angle $(\varphi)$, deg & 0 & $0.286 \pm 0.030$ & $0.428 \pm 0.048$ \\
\hline
\end{tabular}

away. The mouse cursor was placed on the top depth level (d/2), to avoid visual discomfort during the interaction with the application controls.

\section{Usability evaluation model}

In order to understand the impact of the stereoscopic effect on the user interaction with the stimuli, usability was chosen as a measure, hence the main hypothesis was established as:

H1: stereoscopic effect impacts the usability of desktop web applications

Usability is one of the most important terms in software engineering and human-computer interaction $(\mathrm{HCl})$. Despite its importance, there is no unified approach for assessing the usability, and choosing among measures presents some difficulties. A review of usability tools used in $\mathrm{HCl}$ mentions over 50 approaches to the problem (Hornbæk, 2006). Nevertheless, there is a certain trend in usability research: the majority of the tools cluster the term into components or usability factors. The analysis of the most popular usability evaluation models, such as: ISO 9126-1 (Padayachee; Kotzé; Van-Der-Merwe, 2010), ISO 9241-11 (Gediga; Hamborg; Düntsch, 1999), IEEE Std. 1061 (Schneidewind, 1992; Dix et al., 2009), REAL (Löwgren, 1993), QUIM (Seffah; Ke-

Table 2. Usability evaluation tools and coincidental usability factors within them used to form the research hypotheses.

\begin{tabular}{|c|c|c|c|c|c|c|c|c|c|c|}
\hline & ISO 9126-1 & ISO 9241-11 & IEEE Std. 1061 & Dix et al. & REAL & QUIM & SUMI & Shackel & Nielsen & WAMMI \\
\hline Efficiency & - & $x$ & - & - & $x$ & $x$ & $x$ & - & $x$ & $x$ \\
\hline Learnability & $x$ & - & $x$ & $x$ & $x$ & - & $x$ & $x$ & $x$ & $x$ \\
\hline Satisfaction & - & $x$ & - & - & - & $x$ & - & $x$ & $x$ & - \\
\hline
\end{tabular}

(x) presented in a model, (-) not presented in a model 
ceci; Donyaee, 2001), SUMI (Kirakowski; Corbett, 1993), Shackel (Shackel, 1991), Nielsen (Nielsen, 1994), Wammi (Kirakowski; Cierlik, 1998) (see Table 2) reveals three main coincidental factors: efficiency, learnability and satisfaction. Therefore, the research hypothesis was accompanied by 3 sub-hypotheses:

\section{$\mathrm{H} 2$ : Stereoscopic effect impacts the efficiency of des- ktop web applications}

H3: Stereoscopic effect impacts the learnability of desktop web applications

H4: Stereoscopic effect impacts the satisfaction of desktop web applications

\subsection{Subjective evaluation}

A modified version of the Computer System Usability Questionnaire (CSUQ) (Lewis, 1993) was used as a post-session questionnaire for estimation of the subjective performance of the stimuli. The modified version (CSUQm) (see Appendix 2) consisted of 18 items in a form of a 7-grade Likert-scale (1 = "Strongly disagree", 7 = "Strongly agree") measuring efficiency, learnability and satisfaction. The modifications to the original CSUQ items were made for better adaptation to the e-commerce nature of the stimuli. Reliability of the modified version was tested using the Cronbach's Alpha method and scored $(=0.95)$, while the subscales reliability ranged from ( $=0.84)$ to $(=0.93)$. According to Kline (2013), values above $(=0.70)$ indicate good reliability, thus the questionnaire was considered as reliable for the study.

\subsection{Objective efficiency}

The task-based efficiency, characterizing a number of tasks completed in a period of time (second), was adopted for the efficiency calculation.

$$
e_{t}=\sum_{i=1}^{N} \frac{E_{i} i}{t_{i}}
$$

Where $\left(E_{i}\right)$ - the participant's effectiveness for a task ( $\left.i\right)$, a binary value which takes 1 when a task is completed successfully and 0 otherwise, $(N)$ - a total number of tasks within a session, $\left(t_{i}\right)$ - time of completion of the task (i).

\subsection{Objective learnability}

A method for objective learnability estimation of software systems (Chistyakov et al., 2016)System Usability Measurement Inventory (SUMI was used to define learnability within groups. According to the method, the objective learnability of a session $(c)$ can be described as an equation:

$$
c=\frac{n \sum_{i=1}^{n} e_{i} \ln \left(t_{i}\right)-\sum_{i=1}^{n} e_{i} \sum_{i=1}^{n} \ln \left(t_{i}\right)}{n \sum_{i=1}^{n} \ln \left(t_{i}\right)^{2}-\left(\sum_{i=1}^{n} \ln \left(t_{i}\right)\right)^{2}}
$$

Where $(n)$ - total number of tests within a session, $\left(e_{i}\right)$ - calculated efficiency for a task $(i)$, and $\left(t_{i}\right)$ - time of completion of the task ( $i$ ) or a number of the tasks completed, depending on chosen definition of a system's efficiency.

Consequently, the overall learnability for all the stimuli could be obtained as a mean among the sessions:

$$
\bar{c}=\frac{1}{N} \sum_{j=1}^{N} c_{j}
$$

Where $(N)$ - number of sessions, $\left(c_{j}\right)$ - calculated learnability for a session (j).

\section{Procedure}

Tasks were performed in a lab environment. On arrival to the experimental setup, all the participants were briefed on the course of the experiment. The 3D group briefing included a short explanation of the stereoscopic setup with further exposure to a 5-minute preparation stereo video clip in order to accommodate the participants to the stereoscopic effect and get them accustomed to the 3D equipment. Further on, the tasks were explained, while the application's structure and its functionality were not disclosed nor displayed prior the very start of the session. After all the tasks were completed, the participants were asked to fill in the CSUQm.

Thus, in correspondence with the hypotheses $(\mathrm{H} 1, \mathrm{H} 2, \mathrm{H} 3$, and $\mathrm{H} 4$ ), the independent variable was defined as the display setup: 3D display (G3D) and 2D display (G2D) groups, while the dependent variables were defined as overall usability, efficiency, learnability, and satisfaction. A convenience sample was used.

A sequence of 10 tasks to be performed by each of the participants was defined to test the hypotheses. The order in the sequence and the tasks themselves remained unchanged across all the sessions.

In turn, the task performance sequence could be separated into 6 steps (see Appendix 1):

- The task description is displayed on the screen, corresponding to the following structure: "Task [Number]. Add to cart [T-shirt Model] in a size [Size])", along with a "START" button, which triggers the task's timer. The user interface is not visible while this screen is shown.

- The user interface of the stimuli is shown to the user. The user is invited to complete the described task using the user interface. No assistance from the observer is offered, unless the user is lost and asks for a help.

- The user triggers the T-shirt menu. This step is started when the menu button is pressed. The click triggers the T-shirt menu to appear. The menu trigger is performed as so-called "Sandwich" button and placed on the bottom right side of the screen. The T-shirt menu is performed as a list of 10 items - T-shirt model names.

- The user chooses the T-shirt model. When the T-shirt model is pressed, the image of the model is changed to the one corresponding to the chosen option along with the T-shirt brand, model name and price, located the top left of the screen.

- The user chooses the size of the model. The size dropdown control is placed below the T-shirt brand, model name and price. When pressed, the list of available sizing options is shown.

- The user presses the "ADD TO CART" button. The "ADD TO CART" button is located to the right of the size selection 
control. When pressed, the task's timer is stopped, and the next task's description is displayed, if the [T-shirt Model] and the size [Size], specified in the tasks description are chosen correctly. If the model or size of the T-shirt are chosen wrong, the user is notified by the observer that the task is performed with an error, the task description is repeated verbally, and the user is instructed to repeat the task from the beginning, while the task timer continues to record the time of completion.

The time of completion of each task and the number of clicks allowed by the user were recorded during the course of the experiment.

A significance level of $p=0.05$ was adopted for the study. Post-hoc anova and Welch Two Sample t-test were used for statistical analysis.

\section{Results}

\subsection{Times of completion}

During the test, times of completion, times of inactivity where no mouse movement was detected (dead-time), and a number of clicks over the stimuli were recorded using Javascript (see Table 3). Mean time spent to complete a session in G3D was ( $N=22, M=143.748 \mathrm{sec}$, $S D=32.010 \mathrm{sec})$, whereas $\mathrm{G} 2 \mathrm{D}$ showed $(N=17$, $M=100.963 \mathrm{sec}, \quad S D=20.400 \mathrm{sec}$ ). Moreover, the number of clicks performed in G3D was $(N=22, M=57.727, S D=6.009)$, in G2D ( $N=17$, $M=55.529, S D=4.913)$. The recorded dead time of the G3D was $(N=22, M=97.078 \mathrm{sec}$, $S D=31.496 \mathrm{sec})$, while in the $G 2 D$ it was $(N=17$, $M=56.833 \mathrm{sec}, S D=20.807 \mathrm{sec}$ ).

Post-hoc Welch Two Sample t-test revealed a significant effect of the display group on the session's time of completion $(t=5.075, d f=$ $35.876, p<0.001)$ and dead-time $(t=4.791, d f$ $=36.245, p<0.001$ ).

\subsection{Objective efficiency}

The efficiency values for each of the sessions were calculated (see Table 3) by applying (1) on the obtained data set. Thereby mean observed efficiency in G3D was ( $N=22$, $M=0.073, S D=0.016)$, in G2D ( $N=17, M=0.103$, $S D=0.018$ ).

Post-hoc Welch Two Sample t-test revealed a significant effect of the perception group on the session's calculated efficiency ( $t=22.850$, $d f=16, p<0.001)$.

\subsection{Objective learnability}

The index of learnability was obtained by applying (2) on the calculated efficiency values. Thus, learnability for G3D was calculated as $(N=22, M=0.024, S D=0.011)$, for $G 2 D$ as $(N=17, M=0.028, S D=0.011)$.
Table 3. Comparison of the recorded, calculated and subjective values within the perception groups. G2D outperformed G3D according to both subjective and objective indicators

\begin{tabular}{|l|r|r|r|r|}
\cline { 2 - 5 } \multicolumn{1}{c|}{} & \multicolumn{2}{c|}{$\begin{array}{c}\text { G3D } \\
\text { (N=22) }\end{array}$} & \multicolumn{1}{c|}{$\begin{array}{c}\text { G2D } \\
\text { (N=17) }\end{array}$} \\
\hline M & \multicolumn{1}{c|}{ SD } & M & SD \\
\hline Time of a session (sec) & 143.748 & 31.010 & $\mathbf{1 0 0 . 9 6 3}$ & 20.400 \\
\hline Dead time (sec) & 97.078 & 31.496 & $\mathbf{5 6 . 8 3 3}$ & 20.807 \\
\hline Efficiency (tasks/sec) & 0.073 & 0.016 & $\mathbf{0 . 1 0 3}$ & 0.018 \\
\hline Learnability & 0.024 & 0.011 & $\mathbf{0 . 0 2 8}$ & 0.011 \\
\hline Overall CSUQm score & 5.098 & 1.075 & $\mathbf{5 . 9 0 8}$ & 0.864 \\
\hline Perceived efficiency & 5.030 & 1.390 & $\mathbf{6 . 2 6 5}$ & 0.719 \\
\hline Perceived learnability & 5.303 & 0.967 & $\mathbf{5 . 7 6 4}$ & 1.054 \\
\hline Satisfaction & 4.962 & 1.129 & $\mathbf{5 . 6 9 6}$ & 1.016 \\
\hline
\end{tabular}

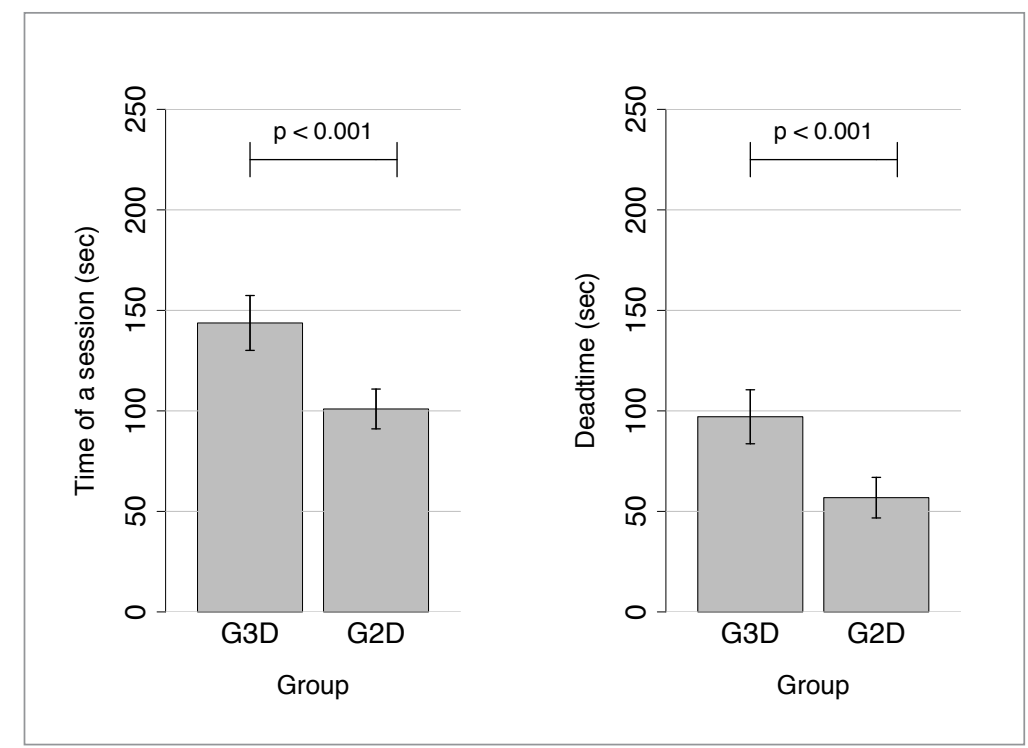

Figure 5. Mean recorded values shown among the groups

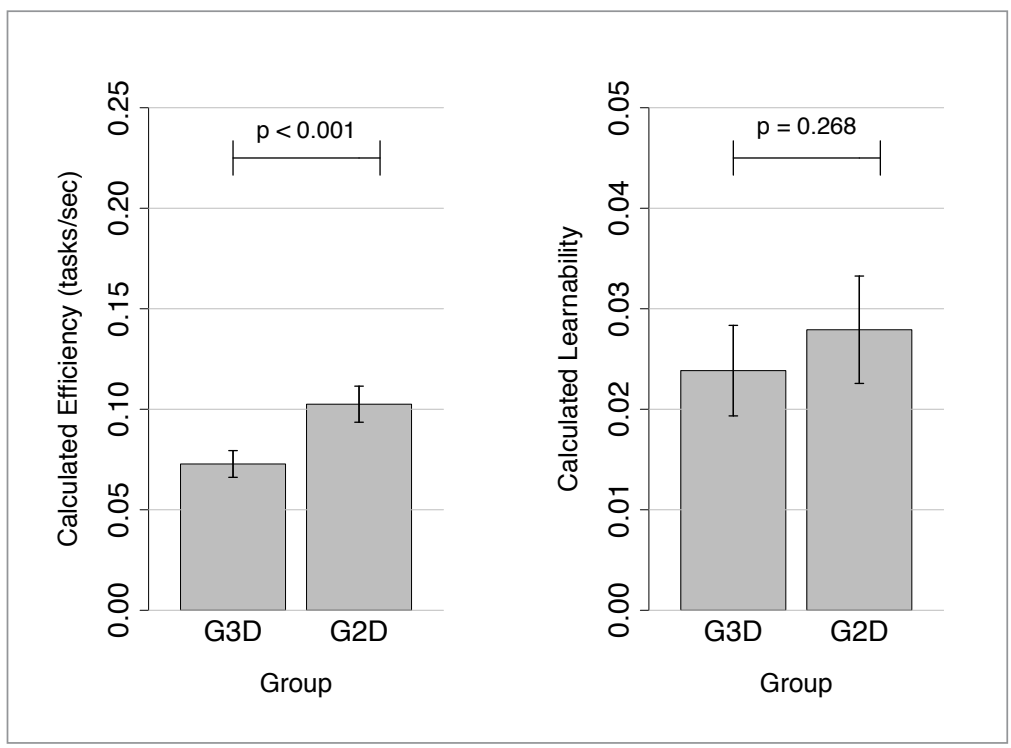

Figure 6. Mean calculated values shown among the groups 


\subsection{Subjective evaluation}

The analysis of CSUQm (see Table 3) shown the highest overall mean score within $\mathrm{G} 2 \mathrm{D}(N=17, M=5.908, S D=0.864)$, while G3D scored $(N=22, M=5.098, S D=1.075)$. The further analysis of the sub-dimensions revealed: (i) perceived learnability score of G2D $(N=17, M=5.764, S D=1.054)$ and G3D $(N=22, M=5.303, S D=0.967)$, (ii) perceived efficiency score of G2D $(N=17, M=6.265, S D=0.719)$ and G3D $(N=22, M=5.030$, $S D=1.390)$, (iii) satisfaction score of $G 2 D(N=17, M=5.696$, $S D=1.016)$ and $G 3 D(N=22, M=4.962, S D=1.129)$.

Post-hoc Welch Two Sample t-test spotted significant differences in the CSUQm overall usability score $(t=2.607$, $d f=36.922, p=0.013)$, as well as perceived efficiency $(t=3.589, d f=32.892, p=0.001)$ and satisfaction $(t=-2.131, d f$ $=36.078, p=0.040$ ).

\section{This experiment among human subjects} revealed a mostly negative impact of S3D on the efficiency, satisfaction, and, consequently, the overall usability of the webapp

\subsection{Overall usability}

Based on the analysis of the recorded times of completion and the questionnaire results, the stereoscopic stimulus performed worse than its $2 \mathrm{D}$ counterpart in terms of efficiency and satisfaction. Thus, $\mathrm{H} 2$ and $\mathrm{H} 4$ can be confirmed: for this sample, the stereoscopic effect has significant negative impact on the efficiency and the satisfaction. At the same time, no significant differences were detected in terms of learnability. Thus, H3 can be denied: for this sample, the stereoscopic effect has no significant negative impact on the learnability.

Overall, the display group negatively impacted 2 out of 3 usability factors. Thus, $\mathrm{H} 1$ can be confirmed: for this sample, the stereoscopic effect has significant negative impact on the usability.

\subsection{Other observations}

Post-hoc Welch two sample t-test revealed significant influence of gender on the error rate $(t=4.250, d f=26.443$, $p<0.001)$. Female participants $(N=7, M=28.710, S D=3.904$, $R g=22-33)$ allowed significantly less errors $(M=2.286$, $S D=2.138)$ during the session than male participants ( $N=32$, $M=28.500, S D=5.764, R g=21-42)$ which allowed $(M=7.750$, $S D=5.657$ ). The comparison of performance by gender within the display groups G3D $(t=2.923, d f=19.563, p=0.009)$ and G2D $(t=4.855, d f=14.430, p<0.001)$ confirmed the finding. Within G3D female participants $(N=4, M=27.250$, $S D=5.764, R g=21-42)$ allowed $(M=3.750, S D=1.500)$ errors, while male participants $(N=18, M=25.170, S D=4.120$, $R g=21-37)$ allowed $(M=8.611, S D=6.298)$ errors. Within G2D female participants $(N=3, M=30.670, S D=2.081, R g=29$ 33) allowed $(M=0.333, S D=0.577)$ errors, while male participants $(N=14, M=32.790, S D=4.677, R g=23-42)$ allowed $(M=6.643, S D=4.700)$ errors.
Anova test shown no significant effect of culture on the performance.

\section{Conclusions}

This exploratory study contributes to the understanding of the user interaction with the 3D displays in the Web environment. Particularly, the study furthers our knowledge on the influence of the stereoscopic effect on the usability of the web applications. This work describes a good foundation for more profound research of confirmatory nature in the same direction.

This experiment among human subjects revealed a mostly negative impact of S3D on the efficiency, satisfaction, and, consequently, the overall usability of the webapp. We assume this influence could be caused by the 3D display setup, the application implementation restrictions, the overall unfamiliarity of the participants with the stereoscopic effect, or complexity of the task. This assumption is confirmed by the large difference between $2 \mathrm{D}$ and $3 \mathrm{D}$ stimuli in the recorded dead time and the absence of such in both objective and subjective learnability.

\section{Future work and discussion}

The detected negative impact of the stereoscopic effect on the usability of the stereoscopic stimulus should not discourage further research in this direction. Stereoscopic displays are growing in number exponentially and have the potential to become ubiquitous in the near future. Correct understanding of the regularities in the user interaction with the 3D displays, as well as apprehension of the influence of the stereoscopic effect on the usability factors could help practitioners to design better user interfaces accommodating the stereoscopic depth.

The method of conversion of 2D web GUI into 3D display user interface used in this study has proven to be reliable and could be applied for more profound confirmatory studies

The method of conversion of 2D web GUI into 3D display user interface used in this study has proven to be reliable and could be applied for more profound confirmatory studies. More detailed studies of user interaction over prolonged periods of time, involving larger samples, and testing different layouts and tasks of different complexity are needed to understand and achieve optimization of design. Further work in this direction could help better understand the impact of the stereoscopic depth on user interaction in general and in particular in the context of the Web.

\section{Acknowledgements}

We are especially grateful to the directorship and staff of the CMP Group that donated their time and facilities for the experimentation. We thank Dr. Jerome C. Foo for assistance with editing of the manuscript. This work was partially done with the support of the Spanish government project MEF3 $\_I R X / S I R X-M M T$ (TEC2014-59679) and the Catalan government Grant 2014-SGR-01452. 


\section{References}

Chen, Qinshui; Wang, Wenmin; Wang, Ronggang; Zhang, Jianlong; Liu, Zhongxin (2014). "An approach to support stereoscopic 3D web". In: Proceedings of the $29^{\text {th }}$ Annual ACM symposium on applied computing - SAC'14. New York, USA: ACM Press, pp. 981-984.

https://doi.org/10.1145/2554850.2555096

Chistyakov, Alexey; González-Zúñiga, Diego; Carrabina, Jordi (2013). "Bringing the web closer: Stereoscopic 3D web conversion". Lecture notes in computer science (including subseries Lecture notes in artificial intelligence and Lecture notes in bioinformatics), pp. 22-25.

https://doi.org/10.1007/978-3-319-03068-5_5

Chistyakov, Alexey; Soto-Sanfiel, Maria T.; Martí, Enric; Carrabina, Jordi (2016). "An HTML tool for production of interactive stereoscopic compositions". Journal of medical systems, v. 40, n. 12, p. 265.

https://doi.org/10.1007/s10916-016-0616-0

Chistyakov, Alexey; Soto-Sanfiel, Maria T.; Martí, Enric; Igarashi, Takeo; Carrabina, Jordi (2016). “Objective learnability estimation of software systems". Lecture notes in computer science (including subseries Lecture notes in artificial intelligence and Lecture notes in bioinformatics), pp. 503-513.

https://doi.org/10.1007/978-3-319-48746-5_52

Chittaro, Luca; Ranon, Roberto (2000). “Adding adaptive features to virtual reality interfaces for e-commerce". In: IntI conf on adaptive hypermedia and adaptive web-based systems. Lecture notes in computer science, pp. 86-97. https://doi.org/10.1007/3-540-44595-1_9

Chittaro, Luca; Ranon, Roberto (2002). “Dynamic generation of personalized VRML content: a general approach and its application to 3D e-commerce". In: Proceedings of the $7^{\text {th }}$ intl conf on 3D web technology, pp. 145-154.

https://doi.org/10.1145/504502.504526

De-Oliveira, Jouvane C.; Shen, Xiaojun; Georganas, Nicolas D. (2000). "Collaborative virtual environment for industrial training and e-commerce", IEEE VRTS. ACM Seoul, 288. https://bit.ly/2wmL9qA

Dix, Alan J. (2009). Human-computer interaction. Springer. ISBN: 9780132398640

Fiorentino, Michele; De-Amicis, Raffaele; Monno, Giuseppe; Stork, André (2002). "Spacedesign: A mixed reality workspace for aesthetic industrial design". In: Proceedings of the $1^{\text {st }}$ Intl symposium on mixed and augmented reality, p. 86.

https://doi.org/10.1109/ISMAR.2002.1115077

Gediga, Günther; Hamborg, Kai-Christoph; Düntsch, Ivo (1999). "The IsoMetrics usability inventory: An operationalization of ISO 9241-10 supporting summative and formative evaluation of software systems". Behaviour \& information technology, v. 18, n. 3, pp. 151-164.

https://doi.org/10.1080/014492999119057

González-Zúñiga, Diego; Chistyakov, Alexey; Orero, Pilar; Carrabina, Jordi (2013). "Breaking the pattern: Study on stereoscopic web perception". Lecture notes in computer science (including subseries Lecture notes in artificial intelligence and Lecture notes in bioinformatics), pp. 26-33. https://doi.org/10.1007/978-3-319-03176-7_4

Han, Soonbo; Lee, Dong-Young (2012). "Extensions for stereoscopic 3D support".

https://bit.ly/2wrnlla

Hayashi, Hidehiko; Shirai, Hideki; Kameda, Masashi; Kunifuji, Susumu; Miyahara, Makoto (2000). "Assessment of extra high quality images using both EEG and assessment words on high order sensations". In: IEEE Intl conf on Systems, man, and cybernetics, pp. 1289-1294.

https://doi.org/10.1109/ICSMC.2000.88603

Heath, Michael D.; Cohen-Gadol, Aaron A. (2012). "Intraoperative stereoscopic 3D video imaging: pushing the boundaries of surgical visualisation and applications for neurosurgical education". British journal of neurosurgery, $\mathrm{v}$. 26, n. 5, pp. 662-667.

https://doi.org/10.3109/02688697.2012.672057

Holliman, Nicolas S.; Dodgson, Neil A.; Favalora, Gregg E.; Pockett, Lachlan (2011). "Three-dimensional displays: A review and applications analysis", IEEE transactions on broadcasting, v. 57, n. 2, pp. 362-371.

https://doi.org/10.1109/TBC.2011.2130930

Hornbæk, Kasper (2006). "Current practice in measuring usability: Challenges to usability studies and research". International journal of human-computer studies, v. 64, n. 2, pp. 79-102.

https://doi.org/10.1016/j.ijhcs.2005.06.002

Ilgner, Justus F. R.; Kawai, Takashi; Shibata, Takashi; Yamazoe, Takashi; Westhofen, Martin (2006). "Evaluation of stereoscopic medical video content on an autostereoscopic display for undergraduate medical education". In: Stereoscopic displays and virtual reality systems XIII - San Jose, CA, Electronic imaging 2006, article n. 605506.

https://doi.org/10.1117/12.647591

Johnson, Andrew; Leigh, Jason; Morin, Paul; Van-Keken, Peter (2006). "GeoWall: stereoscopic visualization for geoscience research and education". IEEE Computer graphics and applications, v. 26, n. 6, pp. 10-14.

https://doi.org/10.1109/MCG.2006.127

Johnston, Semay; Renambot, Luc; Sauter, Daniel (2013). "Employing WebGL to develop interactive stereoscopic 3D content for use in biomedical visualization". In: Dolinsky, M. and McDowall, I. E. (eds.). The engineering reality of virtual reality 2013. Proceedings of the SPIE, article n. 864905. https://doi.org/10.1117/12.2007594

Kirakowski, Jurek; Cierlik, Bozena (1998). "Measuring the usability of web sites". In: Proceedings of the Human Factors and Ergonomics Society annual meeting, pp. 424-428. https://doi.org/10.1177\%2F154193129804200405

Kirakowski, Jurek; Corbett, Mary (1993). "SUMI: The software usability measurement inventory". British journal of educational technology, v. 24, n. 3, pp. 210-212.

https://doi.org/10.1111/j.1467-8535.1993.tb00076.x 
Kline, Paul (2013). Handbook of psychological testing. Routledge. ISBN: 9780415211581

Lewis, James R. (1993). "IBM Computer usability satisfaction questionnaires: Psychometric evaluation and instructions for use". International journal of human-computer interaction, v. 7, n. 1, pp. 57-78.

https://doi.org/10.1080/10447319509526110

Löwgren, Jonas (1993). Human-computer interaction: What every system developer should know. Lund: Studentlitteratur. ISBN: 9144396511

Martínez-Escobar, Marisol; Junke, Bethany; Holub, Joseph; Hisley, Kenneth; Eliot, David; Winer, Eliot (2015). “Evaluation of monoscopic and stereoscopic displays for visual-spatial tasks in medical contexts". Computers in biology and medicine, n. 61, pp. 138-143.

https://doi.org/10.1016/j.compbiomed.2015.03.026

McIntire, John P.; Havig, Paul R.; Geiselman, Eric E. (2012). "What is 3D good for? A review of human performance on stereoscopic 3D displays". SPIE Defense, security, and sensing. International Society for Optics and Photonics, article n. 83830X. https://doi.org/10.1117/12.920017

Mclntire, John P.; Havig, Paul R.; Geiselman, Eric E. (2014). "Stereoscopic 3D displays and human performance: A comprehensive review". Displays, v. 35, n. 1, pp. 18-26.

https://doi.org/10.1016/j.displa.2013.10.004

Murray, Don R.; Jennings, Cullen (1997). "Stereo vision based mapping and navigation for mobile robots". In: IEEE Int/ conf on robotics and automation. Proceedings, 1997, pp. 1694-1699.

https://doi.org/10.1109/ROBOT.1997.614387

Murray, Don R.; Little, James J. (2000). “Using real-time stereo vision for mobile robot navigation". Autonomous robots, v. 8 , n. 2, pp. 161-171.

https://doi.org/10.1023/A:1008987612352

Nielsen, Jakob (1994). Usability engineering. Elsevier Science. ISBN: 9780125184069

Ortiz Jr, Sixto (2010). "Is 3D finally ready for the web?". Computer, v. 43, n. 1, pp. 14-16.

http://doi.ieeecomputersociety.org/10.1109/MC.2010.15

Padayachee, Indira; Kotzé, Paula; Van-Der-Merwe, Alta (2010). "ISO 9126 external systems quality characteristics, sub-characteristics and domain specific criteria for evaluating e-learning systems". The Southern African Computer Lecturers' Association.

https://bit.ly/2LD80I6

Perakakis, Emmanouil; Ghinea, Gheorghita (2015). “HTML5 technologies for effective cross-platform interactive/smart TV advertising". IEEE Transactions on human-machine systems, v. 45, n. 4, pp. 534-539.

https://doi.org/10.1109/THMS.2015.2401975

Schild, Jonas; Bölicke, Liane; LaViola Jr., Joseph J.; Masuch, Maic (2013). "Creating and analyzing stereoscopic 3D gra- phical user interfaces in digital games". In: Proceedings of the Sigchi Conf on human factors in computing systems CHI'13. New York, USA: ACM Press, p. 169.

https://doi.org/10.1145/2470654.2470678

Schild, Jonas; LaViola Jr., Joseph J.; Masuch, Maic (2012). "Understanding user experience in stereoscopic 3D games". In: Proceedings of the 2012 ACM annual conf on human factors in computing systems - $\mathrm{CHI}^{\prime} 12$. New York, USA: ACM Press, p. 89.

https://doi.org/10.1145/2207676.2207690

Schneidewind, Norman F. (1992). "Methodology for validating software metrics". IEEE Transactions on software engineering, v. 18, n. 5, pp. 410-422.

https://doi.org/10.1109/32.135774

Seffah, Ahmed; Kececi, Nihal; Donyaee, Mohammad (2001). "QUIM: a framework for quantifying usability metrics in software quality models". In: Procs $2^{\text {nd }}$ Asia-Pacific conf on quality software, pp. 311-318.

https://doi.org/10.1109/APAQS.2001.990036

Seuntiëns, Pieter J.; Heynderickx, Ingrid E. J.; IJsselsteijn, Wijnand A.; Van-den-Avoort, Paul M. J.; Berentsen, Jelle; Dalm, Iwan J.; Lambooij, Marc T.; Oosting, Willem (2005). "Viewing experience and naturalness of 3D images". SPIE 6016 - Three-Dimensional TV, Video, and Display IV, 601605. SPIE Proceedings, v. 6016. Edited by B. Javidi, F. Okano, and J.-Y. Son, 7 pp. https://doi.org/10.1117/12.627515

Shackel, Brian (1991). "Usability-context, framework, definition, design and evaluation". Human factors for informatics usability. NY: Cambridge University Press, pp. 21-37. ISBN: 0521365708

Van-Beurden, Maurice H. P. H.; IJsselsteijn, Wijnand A.; Juola, James F. (2012). "Effectiveness of stereoscopic displays in medicine: A review". 3D research, v. 3, n. 3, pp. 1-13. https://doi.org/10.1007/3DRes.01(2012)3

Vonkeman, Charlotte; Verhagen, Tibert; Van-Dolen, Willemijn (2017). "Role of local presence in online impulse buying". Information \& management, v. 54, n. 8, pp. 1038-1048. https://doi.org/10.1016/j.im.2017.02.008

Wheatstone, Charles (1838). "Contributions to the physiology of vision. Part the first. On some remarkable, and hitherto unobserved phenomena of binocular vision". Philosophical transactions of the Royal Society of London, v. 128, pp. 371-394.

https://doi.org/10.1098/rstl.1838.0019

Yim, Mark Yi-Cheon; Cicchirillo, Vincent J.; Drumwright, Minette E. (2012). "The impact of stereoscopic three-dimensional (3-D) advertising". Journal of advertising, v. 41, n. 2, pp. 113-128.

https://doi.org/10.2753/JOA0091-3367410208

Zeng, Wanxian; Richardson, Alex (2017). "Beyond 2D product presentation in e-commerce: A literature review". In: Australasian conf on information systems. Hobart, Australia, $11 \mathrm{pp}$. https://bit.ly/2PQmD9t 
Appendix 1. Task sequence
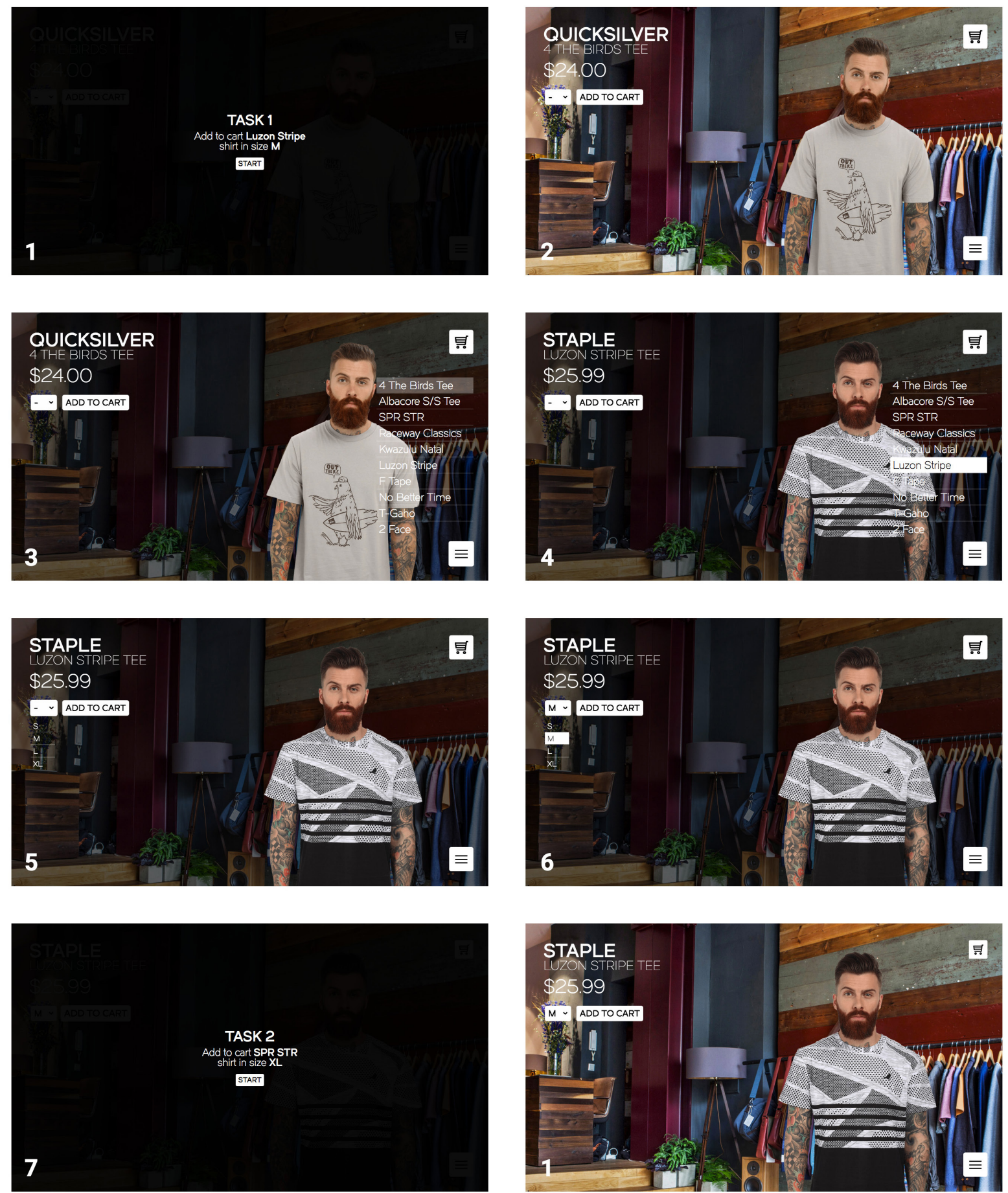

Figure 7. The sequence of the task. The task considered started when the subject clicks the "START" button on the screen (1), while the end of the task is triggered when "ADD TO CART" button is pressed (6). When the task is finished, the new task is shown (7). 


\section{Appendix 2. CSUQm}

Table 4. Internal-consistency reliability estimates (Cronbach Alpha) and minimum inter-item correlations of the modified version of the CSUQ and its subconstructs: efficiency, learnability, and satisfaction.

\begin{tabular}{|c|c|c|c|c|}
\hline $\mathbf{N}$ & Question & Subconstruct & Reliability & $\begin{array}{c}\text { Minimum inter-term } \\
\text { correlation }\end{array}$ \\
\hline 1 & I'm satisfied with how easy it is to use the application & \multirow{6}{*}{ Efficiency } & \multirow{6}{*}{0.93} & \multirow{6}{*}{0.69} \\
\hline 2 & I think that the user interface is friendly and easy to use & & & \\
\hline 3 & I could effectively complete the tasks using this application & & & \\
\hline 4 & I was able to complete the tasks quickly & & & \\
\hline 5 & I was able to efficiently complete the tasks & & & \\
\hline 6 & I felt comfortable using this application & & & \\
\hline 7 & It was easy to learn how to use this application & \multirow{6}{*}{ Learnability } & \multirow{6}{*}{0.84} & \multirow{6}{*}{0.47} \\
\hline 8 & I believe I could become productive quickly using this application & & & \\
\hline 9 & I find user interface of the application convenient & & & \\
\hline 10 & It was easy to find the information I needed & & & \\
\hline 11 & The user interface helped me to complete the tasks & & & \\
\hline 12 & The user interface of this application was easy to understand & & & \\
\hline 13 & I like the way the products were presented & \multirow{6}{*}{ Satisfaction } & \multirow{6}{*}{0.89} & \multirow{6}{*}{0.51} \\
\hline 14 & The user interface of this application was pleasant & & & \\
\hline 15 & Overall, I'm satisfied with this application & & & \\
\hline 16 & Overall, I enjoyed using the application & & & \\
\hline 17 & I would prefer this user interface over the one I usually use & & & \\
\hline 18 & I would recommend this application to the people I know & & & \\
\hline \multicolumn{3}{|c|}{ Overall } & 0.95 & 0.53 \\
\hline
\end{tabular}

\section{Colección EPI Scholar}

Libros científicos de Información, Documentación y Comunicación

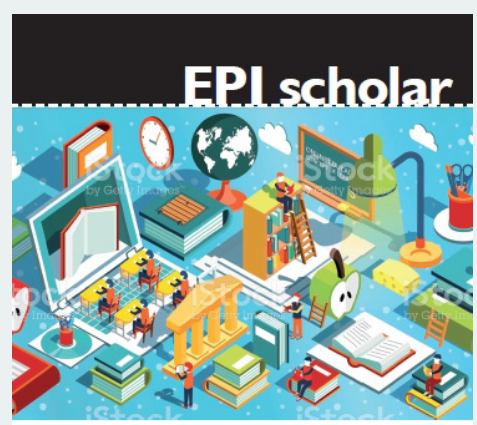

\section{BIBLIOTECAS INTEGRADAS}

PABLO PARRA-VALERO

\section{Bibliotecas integradas de Pablo Parra-Valero}

El modelo de biblioteca integrada o joint use library propone el establecimiento de alianzas cooperativas entre bibliotecas de distinto tipo, normalmente públicas y escolares, para desarrollar su labor conjuntamente, pero sin perder su propia identidad. Su propuesta se sustenta en una concepción de biblioteca única que nace y se planifica con más de una función y ofrece a sus usuarios servicios bibliotecarios diferenciados dentro de una misma instalación, buscando la optimización de espacios y recursos.

Este libro ofrece orientación práctica a los lectores-profesionales que deseen plantear un proyecto de biblioteca integrada o conocer la verdadera dimensión de un modelo de biblioteca tan infrautilizado como desconocido en nuestro país

Parra-Valero, Pablo (2018). Bibliotecas integradas. Barcelona: El profesional de la información, Editorial UOC, colección EPI Scholar n. 8, 136 pp. ISBN: 9788491181375

\section{Información}

http://www.elprofesionaldelainformacion.com/librosEPIScholar.htmI 